\title{
THE RELATIONSHIP BETWEEN PREDATION RISK AND ANTIPREDATOR RESPONSES IN LARVAL ANURANS
}

\author{
RicK A. RELYEA ${ }^{1}$ \\ Department of Biology, University of Michigan, Ann Arbor, Michigan 48109 USA
}

\begin{abstract}
Organisms that produce alternative, nondiscrete phenotypes in response to environmental conditions are expected to alter their phenotypes in relation to the degree of environmental change. This idea has been applied to the evolution of antipredator responses by prey, in which it has been hypothesized that prey should respond more strongly to predators that pose greater mortality risk. In a companion paper, I quantified predatorinduced behavioral and morphological responses in six species of larval anurans across five different predator environments and found that these responses were prey- and predatorspecific. In the present study, I addressed whether the responses were related to the level of predation risk posed by each of the predators. Within each prey species, I found that different predators posed different levels of predation risk; within each predator species, different prey species experienced different levels of risk. The differences in predation risk could be understood mechanistically after I quantified differences among predators in their ability to capture, handle, and consume prey and differences among prey in behavior and morphology. Using multivariate analyses, I found that predation risk had no significant effect on how a given prey responds to predators, although there were significant univariate behavioral effects; higher predation risk was related to greater decreases in activity and greater spatial avoidance. I also examined the relationship between risk and response across the six prey species within a predator treatment and found that higher predation risk across species leads to greater decreases in activity in the presence of Umbra and greater increases in tail depth in the presence of Anax. Thus, while previous studies have found relationships between predation risk and prey response when focusing on relatively few species, few predators, and a single trait, this more powerful test using 30 predator-prey combinations and nine traits suggests that the relationship is not well supported. This finding arises from the fact that larval anurans, as well as many other taxa, exhibit predator- and prey-specific behavioral and morphological changes in response to predator- and prey-specific risk.
\end{abstract}

Key words: antipredator defense; behavior; capture efficiency; handling time; interspecific interactions; larval anurans; morphology; palatability; predation risk.

\section{INTRODUCTION}

Organismal phenotypes are a product of their phylogenetic history and their current environment. A number of investigators have demonstrated that phylogeny can affect several types of traits including life history and morphology (Losos 1990, Reznick et al. 1990, Schluter 1994, Grant and Grant 1995, McPeek 1997, Borash et al. 1998). However, the evolution of environmentally induced traits (i.e., phenotypic plasticity) is less well understood (Bradshaw 1965, Schlichting 1986, Sultan 1987, West-Eberhard 1989, Travis 1994, Via et al. 1995). Theoretical models suggest that plasticity should evolve when populations experience environmental heterogeneity and there are fitness trade-offs among alternative phenotypes such that no single phenotype experiences superior fitness in all

Manuscript received 19 November 1998; revised 23 November 1999; accepted 14 January 2000; final version received 7 February 2000.

${ }^{1}$ Present address: Department of Biological Sciences, University of Pittsburgh, Pittsburgh, Pennsylvania 15260 USA. E-mail: relyea+@ pitt.edu environments (Via and Lande 1985, Gomulkiewicz and Kirkpatrick 1992, Moran 1992). Recent empirical studies support these predictions (Havel and Dodson 1987, Kingsolver 1995a, b, Dudley and Schmitt 1996, Van Buskirk and Relyea 1998).

A common type of phenotypic plasticity is predatorinduced plasticity. Many taxa respond to predators by altering their behavior including spatial avoidance, activity reduction, and temporal changes in behavioral cycles (reviewed by Hassell and Southwood 1978, Dill 1987, Sih 1987, Lima and Dill 1990). Some aquatic species can also alter their life history (Crowl and Covich 1990, Skelly and Werner 1990, Ball and Baker 1996). Others alter their morphology by forming defensive armor and spines (reviewed by Havel 1987, Harvell 1990) or by altering their body shape to foil gape-limited predators (Brönmark and Miner 1992, Kusch 1993, Pettersson and Brönmark 1997) or improve swimming ability to escape predators (McCollum and Van Buskirk 1996).

Because most predator-induced responses are commonly considered adaptive (e.g., reduced activity reduces predation risk; Woodward 1983, Lawler 1989, 
Skelly 1994, Anholt et al. 1996), it has been proposed that the magnitude of antipredator response should be related to the magnitude of risk posed by the predator (Havel 1987, Sih 1987, Lima and Dill 1990). Indeed, there is a substantial amount of evidence that prey respond weakly or nonsignificantly to predators that pose little or no predation risk, whereas prey respond strongly to predators that pose a high predation risk (Sih 1987, Kohler and McPeek 1989, Short and Holomuzki 1992, Peckarsky 1996). These studies have been informative in developing the hypothesis that a prey's magnitude of response to a predator is related to the risk posed by the predator. However, they typically look at only one plastic trait (usually a behavioral trait) and only examine the response to one substantial predation threat. As a result, these types of studies do not constitute a rigorous test of the general hypothesis that antipredator responses of prey are directly related to predation risk. If the hypothesis were true, then prey should respond to predators by using a scaled response of all antipredator traits within its repertoire to match the risk of a particular predator. An alternative hypothesis is that different traits are useful against different predators, causing prey to use a unique suite of responses against each predator species, i.e., responses to different predators are not simply scaled responses. For example, prey might reduce activity in the presence of a moderately risky predator, but use spatial avoidance against a highly risky predator. In this case, we would not expect a uniform and direct relationship between the magnitude of antipredator response and predation risk for any one trait.

In a companion paper, hereafter termed the "plasticity experiment" (Relyea 2001), I reared six species of larval anurans in five different predator environments to document the plasticity of morphological and behavioral traits of prey in response to different predators. In this earlier experiment, I reared three springbreeding anuran species (wood frogs, Rana sylvatica; leopard frogs, R. pipiens; and toads, Bufo americanus) in the presence of no predators, mudminnows (Umbra limi), dragonfly larvae (Anax spp.), adult newts (Notophthalmus viridescens), or predaceous diving beetle larvae (Dytiscus sp.). I later reared three summerbreeding anuran species (gray treefrogs, Hyla versicolor; green frogs, $R$. clamitans; and bullfrogs, $R$. catesbeiana) in the presence of no predators, Umbra, Anax, larval tiger salamanders (Ambystoma tigrinum), or giant water bug adults (Belostoma sp.). Two of the predators were changed to reflect the temporal change in relative abundance of predators in natural ponds (i.e., adult Notophthalmus and Dytiscus were much less abundant in the summer). During the five-week period that the prey were exposed to the predator environments, I quantified both activity and spatial distribution of the prey using visual observations. Upon termination of the experiment, I quantified differences in relative morphology among prey species and among predator treatments. Within each prey species, different predators induced different antipredator responses; within a given predator species, different prey exhibited different antipredator responses. Thus, from this earlier experiment, we know how six species of larval anurans respond behaviorally and morphologically to five different predator environments.

Because each anuran prey responded differently to different species of predators and the six anuran prey responded differently to the same predator, we also might expect predation risk to vary among the 30 predator-prey combinations. Mechanistically, differences in predation risk should be related to differences in the predators' abilities to capture, handle, and consume the prey. In the present study, I quantified predation rates and predator behavior (the ability to capture, handle, and consume prey) for each of the 30 predator-prey combinations used in the earlier experiment. These data can be combined with the results of the plasticity experiment (Relyea 2001) to examine how well predation risk correlates with the magnitudes of phenotypic response (the change in the value of a trait) both within and across prey species. To better understand the mechanistic role of behavioral and morphological traits of prey in determining predation risk, one can correlate prey phenotypes (the value of a trait) from the plasticity experiment against predation risk. Because predation risk is the result of several sequential events (prey encounter, prey capture, prey handling, and prey consumption), we can further examine at what point in the predation process the prey traits become important, by correlating the prey phenotypes from the plasticity experiment against the predator behaviors. In summary, I combined the prey response data from the plasticity experiment with the predation risk and predator behavior data from the present experiment to address the following five hypotheses: (1) predation risk is prey and predator specific, (2) predator behavior is prey- and predator-specific, (3) the magnitudes of phenotypic response exhibited by the prey are related to predation risk, (4) differences in prey phenotypes affect predation rate, and (5) differences in prey phenotypes affect predator behavior.

\section{Methods}

I conducted two experiments. In the first experiment, hereafter termed the "predation rate experiment," I quantified mortality rates of the six tadpole species in each of the five predator environments. In the second experiment, henceforth termed the "predator behavior experiment," I used a highly controlled environment to visually observe the capture probability, consumption probability, and handling time for each predatorprey interaction. For all experiments, animals were collected from natural and experimental ponds in the Edwin S. George Reserve (ESGR) and the Michigan Department of Natural Resources' Saline Fish Hatchery, both located in southeast Michigan. Tadpoles were col- 
TABLE 1. Sizes of predators $(\mathrm{mm})$ used in the predation rate experiment and the predator behavior experiment.

\begin{tabular}{|c|c|c|c|c|c|c|c|c|}
\hline \multicolumn{9}{|l|}{ A) Spring } \\
\hline Prey & Umbra & Anax & $\begin{array}{l}\text { Notoph- } \\
\text { thalmus }\end{array}$ & Dytiscus & Umbra & Anax & $\begin{array}{l}\text { Notoph- } \\
\text { thalmus }\end{array}$ & Dytiscus \\
\hline $\begin{array}{l}\text { Leopard frogs } \\
\text { Toads } \\
\text { Wood frogs }\end{array}$ & $\begin{array}{l}71 \pm 1 \\
70 \pm 2 \\
72 \pm 1\end{array}$ & $\begin{array}{l}41 \pm 2 \\
48 \pm 2 \\
43 \pm 1\end{array}$ & $\begin{array}{l}40 \pm 2 \\
38 \pm 1 \\
41 \pm 1\end{array}$ & $\begin{array}{l}37 \pm 2 \\
40 \pm 2 \\
33 \pm 1\end{array}$ & $\begin{array}{l}71 \pm 2 \\
66 \pm 2 \\
73 \pm 3\end{array}$ & $\begin{array}{l}44 \pm 3 \\
45 \pm 4 \\
43 \pm 2\end{array}$ & $\begin{array}{l}39 \pm 2 \\
37 \pm 1 \\
39 \pm 1\end{array}$ & $\begin{array}{l}38 \pm 1 \\
39 \pm 2 \\
30 \pm 1\end{array}$ \\
\hline
\end{tabular}

B) Summer

\begin{tabular}{|c|c|c|c|c|c|c|c|c|}
\hline \multirow[b]{2}{*}{ Prey } & \multicolumn{4}{|c|}{ Predation rate experiment } & \multicolumn{4}{|c|}{ Predator behavior experiment } \\
\hline & Umbra & Anax & Ambystoma & Belostoma & Umbra & Anax & Ambystoma & Belostoma \\
\hline Treefrogs & $68 \pm 2$ & $51 \pm 1$ & $49 \pm 1$ & $22 \pm 0$ & $67 \pm 1$ & $52 \pm 1$ & $50 \pm 2$ & $22 \pm 0$ \\
\hline Green frogs & $66 \pm 1$ & $52 \pm 1$ & $51 \pm 1$ & $21 \pm 0$ & $68 \pm 2$ & $51 \pm 3$ & $52 \pm 4$ & $21 \pm 0$ \\
\hline Bullfrogs & $63 \pm 1$ & $49 \pm 1$ & $45 \pm 1$ & $22 \pm 0$ & $67 \pm 1$ & $49 \pm 2$ & $51 \pm 1$ & $22 \pm 0$ \\
\hline
\end{tabular}

Notes: All measurements were made using standard measurement techniques for each species: Umbra were measured from the snout to the beginning of the caudal fin; Ambystoma and Notophthalmus were measured from the snout to vent; Anax, Belostoma, and Dytiscus were measured for total length. Data are means \pm 1 SE.

lected as eggs and hatched in 100-L wading pools containing aged well water to keep them predator naive. The tadpoles were fed rabbit chow ad libitum until ready to be placed into the experiments. Predators were captured from ponds and fed tadpoles under laboratory conditions until needed in the experiments. In both experiments, I tried to standardize hunger levels by not feeding the predators for $24 \mathrm{~h}$ prior to the experiments.

As an aside, testing naive tadpoles is the appropriate approach to understanding relationships between prey response and predation risk (i.e., the rate of predation) because the underlying hypothesis is that uninduced tadpoles that face the largest threat of mortality will exhibit the strongest antipredator response. Predation trials using tadpoles that were previously induced by their respective predators would be inappropriate, because differences in predation risk across predators would be due to both the predator that is present and the previous amount of phenotypic induction. Further, the estimates of predation risk in this study are made under highly artificial conditions that do not permit microhabitat separation between predators and prey that may occur in natural ponds. However, this approach (1) is the most feasible for such a large number of predator-prey combinations, (2) may be the most appropriate when prey responses also are quantified under conditions that do not permit microhabitat separation, and (3) follows conventional estimates of predation risk (Azevedo-Ramos et al. 1992, Chovanec 1992, Skelly 1994).

\section{Predation rate experiment}

The predation rate experiment was conducted in 40 $\mathrm{L}$ aquaria containing aged well water, $2 \mathrm{~L}$ of small, washed gravel as a substrate, and two handfuls of the aquatic macrophyte Elodea for structural complexity. Because of differences in breeding times of the anurans, predation rate experiments were conducted separately by prey species. For each prey species, 10 pred- ator-naive tadpoles were placed into each aquarium and the aquaria were randomly assigned one of five predator treatments. For the spring-breeding anurans (wood frogs, leopard frogs, and toads), the predator treatments were adult mudminnows, larval dragonflies, adult newts, larval predaceous diving beetles, and a no-predator control. Leopard frogs and toads frequently coexist with all four species of predators whereas wood frogs frequently coexist with all but the mudminnows on the ESGR (E. E. Werner et al., unpublished data). For the summer-breeding anurans (bullfrogs, green frogs, and gray treefrogs), the predator treatments were adult mudminnows, larval dragonflies, larval tiger salamanders, adult giant water bugs, and a no-predator control (Table 1). Green frogs and treefrogs frequently coexist with all four species of predators whereas bullfrogs frequently coexist with all but the tiger salamanders on the ESGR (E. E. Werner et al., unpublished data). Prey ranged in mass from 21 to $40 \mathrm{mg}$ (wood frogs, range $=26-39 \mathrm{mg}$; leopard frogs, range $=22-36 \mathrm{mg}$; toads, range $=21-26 \mathrm{mg}$; bullfrogs, range $=23-29 \mathrm{mg}$; green frogs, range $=22-30 \mathrm{mg}$; and treefrogs, range $=28-$ $40 \mathrm{mg})$.

Predators were initially caged to allow the prey to behaviorally adjust to their presence. Behavioral responses of predator-naive prey typically occur in a matter of minutes (unpublished data). Predator cages were constructed of plastic, slotted drain pipe $(10 \times 11 \mathrm{~cm})$ covered on each end with 2-mm fiberglass screening fastened with rubber bands; a small piece of polystyrene was added to make the cage float. Each predator was fed a single tadpole while in the cage to help ensure that the predators were emitting a predator cue prior to their release (Petranka et al. 1987, Kats et al. 1988, McCollum and Leimberger 1997). After being held for at least $12 \mathrm{~h}$, the predators were released and each predator species was allowed to feed until it had consumed approximately half of the prey or until $4 \mathrm{~h}$ had passed, whichever occurred first. If all predators had 
been allowed to feed on tadpoles for $4 \mathrm{~h}$, the more voracious predators would have quickly consumed most of the tadpoles (a high rate of predation) and then fed very little for the remainder of the time, resulting in an artificially low estimate of predation risk. A large number of replicates was required; thus, aquaria were rinsed and reused so that trials could be conducted over several days. Because of the variability in available predators, the number of replicates for each predatorprey combination varied from 8 to 23 replicates.

\section{Predator behavior experiment}

The predator behavior experiment was designed to examine the mechanisms behind the outcome of the predation trials. For each predator behavior trial, I placed 20 predator-naive tadpoles into $20-\mathrm{L}$ aquaria that contained $10 \mathrm{~L}$ of conditioned well water. I lined the bottom of each aquarium with nylon screening (0.7$\mathrm{mm}$ mesh size, held down with small rocks) to provide a substrate for the walking predators without obstructing my view of the predation events. Two aquaria were observed simultaneously for $\sim 1 \mathrm{~h}$; the predator treatment observed during a time period was random and occurred over several weeks because of the long observation times required and the breeding phenology of the prey species. Single predators were added to all of the aquaria and given time to adjust to their new environment (Table 1). Tadpoles were added later to each aquarium when an observation period began. For each prey species, 20 tadpoles ranging in mass from 21 to $46 \mathrm{mg}$ were introduced into each aquarium (range of mean masses on each observation day: wood frogs $=34-37 \mathrm{mg}$; leopard frogs $=34-46 \mathrm{mg}$; toads $=21-$ $30 \mathrm{mg}$; bullfrogs $=28-35 \mathrm{mg}$; green frogs $=24-35$ $\mathrm{mg}$; and treefrogs $=27-30 \mathrm{mg}$ ). The hour-long observations quantified predator capture efficiency (the proportion of predator strikes that resulted in a prey capture), palatability (the proportion of captured prey that were consumed), and mean handling time (from the time of a prey capture until the predator showed interest in other prey). Because of the uneven number of available predators of each species and the lack of Umbra strikes upon the summer prey species, the number of replicates per predator-prey combination in this experiment ranged from 6 to 14 replicates.

\section{Statistical analysis}

The first analyses tested the hypotheses that predation rates and predator behavior were prey and predator specific. I conducted separate analyses for the five predator treatments experienced by the spring-breeding anurans (the spring analysis), the five predator treatments experienced by the summer-breeding anurans (the summer analysis), and the three predator treatments common to all six anurans (the combined analysis). For the predation rate experiment, the response variable was the number of tadpoles consumed per hour by an individual predator. For the predator behavior experi- ment, the responses were capture efficiency, palatability, and mean handling time observed in each aquarium. The data in both analyses violated assumptions of normality and homogeneity of errors (e.g., many prey were $100 \pm 0 \%$ palatable). Therefore, all data were analyzed with a nonparametric Kruskal-Wallis test. Because of apparent interactions among the predator and prey combinations, I conducted separate tests (1) for each prey among the predator treatments and (2) across all prey for the Umbra and Anax predators. Nonparametric mean comparison tests were not possible since the treatments were not equally replicated. Predator-prey combinations with less than two replicates were not used in the tests (e.g., there were no replicate estimates of Umbra handling green frogs because Umbra never consumed green frogs in seven trials).

The remaining hypotheses related predation risk and predator behavior to the prey phenotype exhibited in the earlier plasticity experiment (for detailed methodology, see Relyea 2001). In brief, activity level and spatial avoidance of predators were quantified by visual observations (see Plate 1). Changes in relative morphology were quantified by regressing seven linear dimensions (tail depth and length; muscle depth and width; and body depth, length, and width) against a measure of overall size (the first principal component in a principal components analysis). The mean residuals from this regression represent size-adjusted morphology (Van Buskirk and Relyea 1998).

The third hypothesis was that phenotypic responses of prey were related to predation risk. The hypothesis was tested in two ways. The first approach was a within-prey/across-predator analysis, in which I used a multivariate analysis of covariance (MANCOVA) to examine the effect of predation risk on the prey phenotypes quantified in the earlier study (Relyea 2001). The MANCOVA used prey species as a main effect, to control for species-specific phenotypic responses, predation risk as the covariate (log-transformed to improve the linearity of the relationships), and a prey-by-risk interaction term. It is important to note that within prey species, relating predation risk to prey phenotypes is equivalent to relating predation risk to magnitudes of phenotypic response.

The second approach was a within-predator/acrossprey analysis in which I related the predation risk of a single predator on all six prey with the magnitude of phenotypic response induced by the predator on all six prey. Magnitudes of response were calculated by subtracting the value of the predator-induced phenotypes from the phenotypic value expressed in the no-predator control (Relyea 2001). Because there were insufficient degrees of freedom to conduct a MANCOVA as above, I used correlation analyses for Anax and Umbra (the two predators common to all six prey) and then made Bonferroni adjustments for multiple comparisons.

The fourth hypothesis was that the differences in predation rates could in part be explained by differ- 
Plate. 1. Typical responses of wood frog tadpoles to either the absence of predators (top) or the presence of dragonfly predators (bottom). In the inset, I overlaid the outlines of the two phenotypes to accentuate the difference in tail depth (shaded area). Photo taken by David Bay with digital editing by Tom Harper.

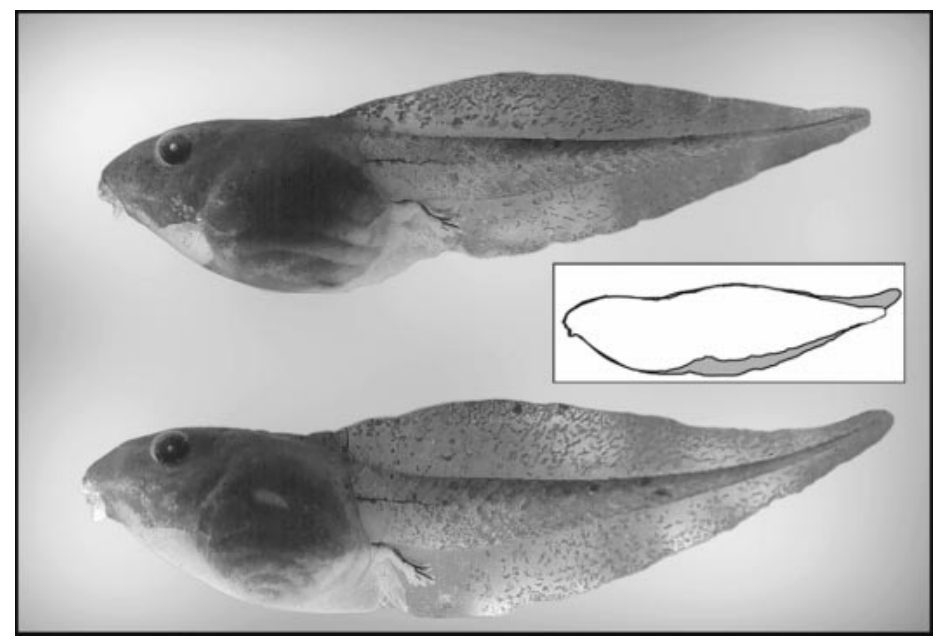

ences in prey phenotypes. To test this hypothesis, I used stepwise regression of prey phenotypes against predation risk for the six prey within a predator treatment (either Anax and Umbra). As mentioned previously, the predation rate experiment and predator behavior experiment used predator-naive tadpoles; thus, if we wish to know how prey phenotype affects predator behavior and predation rate, we must have independent estimates of the behavioral and morphological phenotypes of the predator-naive tadpoles used in the predation experiments. Behavioral responses to predators are rapidly induced (on the order of minutes; unpublished data); therefore the behavioral phenotypes of the tadpoles in the predation experiments should have resembled the predator-induced behavioral phenotypes observed in the plasticity experiment (Relyea 2001). In contrast, morphological phenotypes change more slowly (on the order of weeks); therefore, the morphological phenotypes of the tadpoles in the predation experiments should have resembled the no-predator morphology observed in the plasticity experiment (Relyea 2001). Thus, I regressed the predator-induced behavioral phenotypes and the no-predator-induced morphological phenotypes of the six prey against predation rates on the six prey. These analyses were conducted separately for each predator.

The fifth hypothesis was that differences in predation rates could be mechanistically understood as differences in prey phenotypes that affect a predator's behavior during the predation process (the predator's ability to capture, handle, and consume a prey). To test this hypothesis, I correlated prey phenotypes with the ability of Anax to capture, handle, and consume prey. In this analysis, I could only use the Anax predator treatments because Anax were present for all six prey species and Anax consumed prey of all six species (Umbra only consumed three of the six species). Similar to the test of hypothesis four, I used the morphological phenotypes of prey reared in the absence of predators
(Relyea 2001). I did not correlate prey behavior with predator behavior, because I expected differences in prey activity level and spatial distribution to only affect a prey's encounter rate with predators but not affect a prey's ability to escape capture, a prey's palatability, or the time it takes a predator to consume a struggling prey.

In all of these analyses, there is the potential for concern that prey density was not held constant in the plasticity experiment (1.4 prey/L), predation risk experiment $(0.3$ prey/L), and predator behavior experiment $(2.0$ prey/L). In the plasticity experiment, which lasted five weeks, both behavior and morphology could be altered by the presence of the predator. In contrast, the predation risk and predator behavior experiments were of very short duration (1-4 h), allowing only behavior to change among predator treatments. Thus, comparisons of predation risk and the morphological responses of tadpoles should be unaffected by differences in tadpole density. Whereas it is unclear how spatial avoidance might be affected by changes in density, it is likely that general activity level could differ between experiments because of differences in both density and food resources. However, it is unlikely that there will be any qualitative differences in the activity level among predator treatments. A limited number of behavioral observations taken on the predation rate experiment prior to releasing the predators from their cages supports this assertion (unpublished data).

\section{RESUlts}

\section{Predation rates}

Predators commonly imposed different levels of predation risk on the prey (Table 2, Fig. 1). To simplify the presentation of the results, I defined low predation as 0 to $<1$ deaths $/ \mathrm{h}$, moderate predation as 1 to $<2$ deaths/h, and high predation as $\geq 2$ deaths/h. For the spring-breeding amphibians, all three anurans experi- 
TABLE 2. Results of nonparametric tests of the predation rate, capture efficiency, palatability, and handling time of several predators on each of six larval anuran species.

\begin{tabular}{|c|c|c|c|c|}
\hline \multirow[b]{2}{*}{ Prey } & \multicolumn{4}{|c|}{ Kruskal-Wallis test statistic $(P)$} \\
\hline & Predation rate & Capture efficiency & Palatability & Handling time \\
\hline \multicolumn{5}{|c|}{ Comparisons among predators for spring prey $\dagger$} \\
\hline Leopard frog & $18.6(<0.001)$ & $9.5(0.023)$ & $9.7(0.021)$ & $11.1(0.011)$ \\
\hline Toad & $31.9(<0.001)$ & $12.9(0.005)$ & $16.5(0.001)$ & $9.6(0.002)$ \\
\hline Wood frog & $54.1(<0.001)$ & $13.9(0.003)$ & $7.9(0.047)$ & $18.5(<0.001)$ \\
\hline \multicolumn{5}{|c|}{ Comparisons among predators for summer prey $\dagger$} \\
\hline Bullfrog & $33.6(<0.001)$ & $9.2(0.010)$ & $4.2(0.124)$ & $11.8(0.003)$ \\
\hline Green frog & $31.3(<0.001)$ & $7.8(0.050)$ & $1.7(0.435)$ & $9.9(0.007)$ \\
\hline Treefrog & $34.8(<0.001)$ & $9.9(0.007)$ & $0.0(1.000)$ & $14.8(0.001)$ \\
\hline \multicolumn{5}{|c|}{ Comparisons among prey for a given predator } \\
\hline Umbra & $66.7(<0.001)$ & $1.9(0.596)$ & $6.4(0.041)$ & $4.3(0.037)$ \\
\hline Anax & $38.3(<0.001)$ & $18.4(0.003)$ & $27.3(<0.001)$ & $13.7(0.009)$ \\
\hline
\end{tabular}

Notes: Analyses were first conducted across predator treatments within each anuran species and then across all six anuran species within each predator treatment that the six prey had in common. Numbers in parentheses are $P$ values.

$\dagger$ Bonferroni criteria, $P<0.017$.

$\ddagger$ Bonferroni criteria, $P<0.025$

enced significantly different predation rates among the five predator environments. Toads experienced low predation by all predators. In contrast, wood frogs experienced low predation by Dytiscus, moderate predation by Anax and Notophthalmus, and high predation by Umbra. Leopard frogs experienced low predation by Dytiscus and moderate predation by Umbra, Anax, and Notophthalmus.

The three summer-breeding anurans also experienced significantly different predation rates among the five predator environments (Table 2, Fig. 1). Bullfrogs experienced high predation by Ambystoma and low predation by Umbra, Anax, and Belostoma. Similarly, green frogs experienced moderate predation by $\mathrm{Am}$ bystoma and low predation by the other three predators. Treefrogs experienced moderate predation by Ambystoma and Anax and low predation by Umbra and Belostoma.

The combined analysis of all six anurans experiencing the common Umbra and Anax treatments demonstrated significant differences among prey in their susceptibility to a particular predator (Table 2, Fig. 1). In the presence of Umbra, predation was low on green frogs, bullfrogs, toads, and treefrogs, moderate on leopard frogs, and high on wood frogs. In the presence of Anax, the rankings were similar except that predation was higher on treefrogs and lower on wood frogs.

\section{Predator behavior}

Observing actual predation events provided the mechanistic explanations for why predators differed in their consumption of tadpoles (Tables 2-4). When the spring predators were offered larval wood frogs, there were significant differences in capture efficiency and handling time, but not palatability (Tables 2 and 3). Umbra were the most efficient at capturing wood frogs, whereas Anax, Notophthalmus, and Dytiscus were progressively less efficient, respectively. Umbra had the fastest handling times, requiring $28 \mathrm{~s}$ to consume wood frogs, Notophthalmus took twice as long, and Anax took five times as long. Dytiscus took nearly 75 times as long, requiring more than half an hour to handle each tadpole. All four predators found wood frogs to be quite palatable.

The predators behaved quite differently when feeding on leopard frogs (Tables 2 and 3). There were significant differences among predators in handling time and nearly significant differences in capture efficiency and palatability. Umbra and Anax had similarly high capture efficiencies while Notophthalmus and Dytiscus missed the leopard frogs with nearly half of their strikes. Leopard frogs were moderately unpalatable to Umbra (being rejected half the time), but fully palatable to the other three predators. Umbra, Anax, and Notophthalmus spent similar amounts of time handling leopard frogs (1-2 min), but Dytiscus took $>20 \mathrm{~min}$ to handle leopard frogs.

Predators also differed in how they captured, handled, and consumed toads (Tables 2 and 3). Toads were easily caught by Umbra and Anax and almost immediately rejected due to their high unpalatability. The most common reaction of these two predators was to not strike at all. In fact, I conducted observations on a total of 13 Umbra predators and only two struck at toads; in both cases, the toads were spit out. In comparison, Notophthalmus successfully captured toads two-thirds of the time and found toads to be moderately unpalatable, whereas Dytiscus captured toads on half of their strikes and found toads to be completely palatable.

The summer predators also differed in how efficiently they captured, handled, and consumed tadpoles (Tables 2 and 4). For bullfrogs, Belostoma missed with three-fourths of their strikes, Anax missed with half of their strikes, and Ambystoma missed with about onefourth of their strikes. In six trials, I only observed one Umbra strike at bullfrogs and it never missed. There were no differences in palatability of bullfrogs among 

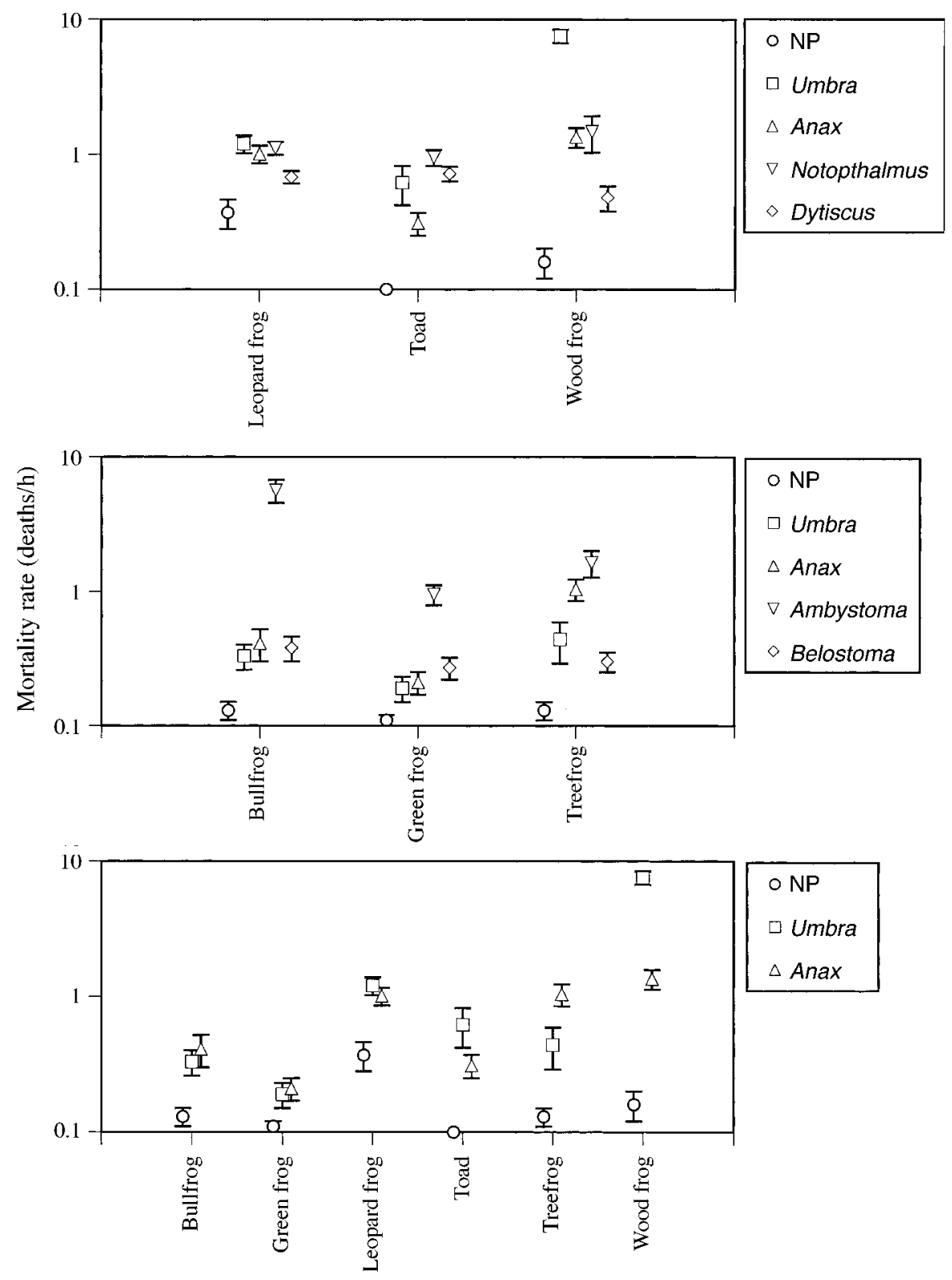

FIG. 1. Predation rates of several predators on six species of larval anurans. The analysis was split to examine the mortality rates of tadpoles in five predator environments for spring-breeding predators (upper panel) and summer-breeding predators (middle panel). The third analysis was of mortality rates on all six tadpole species in the three common predator environments (lower panel). Log scales were used to better illustrate the data; as a result, 0.1 was added to all responses since some response values were zero and undefined on a log scale. The legends indicate the genus of predator used in the trial with the exception of "NP," which indicates that no predator was present. Data are means \pm 1 SE.

Belostoma, Ambystoma, and Anax, all three palatabilities were relatively high $(>80 \%)$. The one Umbra that struck at bullfrogs spit out all captured bullfrogs, suggesting high unpalatability. There also were significant differences in handling times of bullfrogs; Anax and Ambystoma handled bullfrogs in 1.5-2.0 min while $B e$ lostoma required nearly $30 \mathrm{~min}$.

Green frogs differed in handling time among predators but they did not differ in their palatability or capture efficiency with the summer predators, likely due to the low number and highly variable replicates in the Umbra treatment (Tables 2 and 4). Umbra, Anax, and Ambystoma had capture efficiencies similar to green frogs ( $\sim 50 \%)$, but Belostoma missed green frogs on nearly four of every five attempts. Palatability of green frogs to Anax, Ambystoma, and Belostoma was high (96-100\%); Umbra rarely struck at green frogs; in seven trials, the one Umbra that captured a green 
TABLE 3. Observations of four predators handling spring-breeding tadpoles ( $\bar{x} \pm 1 \mathrm{SE})$.

\begin{tabular}{|c|c|c|c|}
\hline Predator & Capture efficiency & Palatability & Handling time (min:s) \\
\hline \multicolumn{4}{|l|}{ Toad tadpoles } \\
\hline Umbra & $1.00 \pm 0.00(2)$ & $0.00 \pm 0.00$ & never ate $(13) \dagger$ \\
\hline Anax & $1.00 \pm 0.00(6)$ & $0.08 \pm 0.08(6)$ & $02: 08 \pm 00: 00(1) \ddagger$ \\
\hline Notophthalmus & $0.67 \pm 0.09(10)$ & $0.43 \pm 0.11(10)$ & $00: 44 \pm 00: 10(8)$ \\
\hline Dytiscus & $0.48 \pm 0.08(6)$ & $1.00 \pm 0.00(6)$ & $17: 24 \pm 03: 34(6)$ \\
\hline \multicolumn{4}{|c|}{ Wood frog tadpoles } \\
\hline Umbra & $0.92 \pm 0.04(7)$ & $0.83 \pm 0.09$ & $00: 28 \pm 0: 07$ \\
\hline Anax & $0.63 \pm 0.10(6)$ & $1.00 \pm 0.00(6)$ & $02: 34 \pm 00: 18(6)$ \\
\hline Notophthalmus & $0.57 \pm 0.06(7)$ & $1.00 \pm 0.00(7)$ & $00: 56 \pm 00: 12(7)$ \\
\hline Dytiscus & $0.40 \pm 0.06(4)$ & $1.00 \pm 0.00(4)$ & $34: 35 \pm 10: 15(4)$ \\
\hline \multicolumn{4}{|c|}{ Leopard frog tadpoles } \\
\hline Umbra & $0.82 \pm 0.09$ & $0.49 \pm 0.14(10)$ & $01: 49 \pm 00: 36(8)$ \\
\hline Anax & $0.80 \pm 0.12$ & $1.00 \pm 0.00$ & $02: 05 \pm 00: 17$ (4) \\
\hline Notophthalmus & $0.45 \pm 0.06(4)$ & $0.95 \pm 0.05$ & $01: 09 \pm 00: 05$ (4) \\
\hline Dytiscus & $0.45 \pm 0.09$ (4) & $1.00 \pm 0.00(4)$ & $23: 12 \pm 02: 21$ \\
\hline
\end{tabular}

Note: Sample sizes are in parentheses.

$\dagger$ Only two of 13 Umbra struck at toads, and all were spit out.

$\ddagger$ Only one of the seven Anax consumed any of the toads captured.

frog ended up rejecting it, suggesting that green frogs may be unpalatable to Umbra. Once captured, Anax and Ambystoma handled green frogs relatively quickly (1-2 min) but Belostoma required more than an hour to handle a green frog tadpole.

Treefrogs were fully palatable to all four predators but there were predator differences in how efficiently they captured and handled treefrogs (Tables 2 and 4). Anax and Belostoma successfully captured treefrogs in one-third of their attempts, whereas Ambystoma were successful in about three-fourths of their strikes. Only one of 14 Umbra ever struck at treefrogs; it missed one tadpole and captured the other. Handling treefrogs was relatively fast for Anax and Ambystoma (0.5-1.0 min), but required nearly $17 \mathrm{~min}$ for Belostoma.

In the combined analysis, predator behavior was compared across all six prey species for either Anax or Umbra (Tables 2 and 4). Umbra were most efficient at capturing toads and became progressively less efficient with wood frogs, leopard frogs, and green frogs. However, because Umbra rarely struck at toads and green frogs, the data were highly variable and not significant (bullfrogs and treefrogs were not included in the analysis since only one Umbra ever struck at these prey species). Anax capture efficiency significantly differed among prey; it was highest with toads, lower with wood frogs and leopard frogs, and lowest with bullfrogs, treefrogs, and green frogs. In terms of palatability, Umbra tended to find wood frogs highly palatable, leopard frogs moderately palatable, and toads completely unpalatable, but the differences were nonsignificant $(P=$ 0.037) following Bonferroni adjustment for multiple

TABLE 4. Observations of four predators handling summer-breeding tadpoles ( $\bar{x} \pm 1 \mathrm{SE})$.

\begin{tabular}{|c|c|c|c|}
\hline Predator & Capture efficiency & Palatability & Handling time (min:s) \\
\hline \multicolumn{4}{|c|}{ Treefrog tadpoles } \\
\hline Umbra & $0.50 \pm 0.00$ & $1.00 \pm 0.00$ & $03: 54 \pm 00: 00(1) \dagger$ \\
\hline Anax & $0.39 \pm 0.08$ (9) & $1.00 \pm 0.00(8)$ & $01: 00 \pm 00: 08(8)$ \\
\hline Ambystoma & $0.72 \pm 0.04(6)$ & $1.00 \pm 0.00(6)$ & $00: 39 \pm 00: 08(6)$ \\
\hline Belostoma & $0.36 \pm 0.07(7)$ & $1.00 \pm 0.00(7)$ & $17: 11 \pm 03: 01(7)$ \\
\hline \multicolumn{4}{|c|}{ Green frog tadpoles } \\
\hline Umbra & $0.50 \pm 0.50$ & $0.00 \pm 0.00(1)$ & never ate $\quad(7) \ddagger$ \\
\hline Anax & $0.41 \pm 0.09(6)$ & $0.96 \pm 0.03(6)$ & $01: 42 \pm 00: 21(6)$ \\
\hline Ambystoma & $0.58 \pm 0.06(6)$ & $1.00 \pm 0.00(6)$ & $00: 58 \pm 00: 10(6)$ \\
\hline Belostoma & $0.17 \pm 0.07(7)$ & $1.00 \pm 0.00(4)$ & $65: 24 \pm 07: 41(4)$ \\
\hline \multicolumn{4}{|c|}{ Bullfrog tadpoles } \\
\hline Umbra & $1.00 \pm 0.00$ & $0.00 \pm 0.00$ & never ate $\quad(6) \S$ \\
\hline Anax & $0.54 \pm 0.12(7)$ & $0.80 \pm 0.09(6)$ & $02: 02 \pm 00: 17$ (6) \\
\hline Ambystoma & $0.72 \pm 0.05(6)$ & $0.93 \pm 0.07(6)$ & $01: 35 \pm 00: 24(6)$ \\
\hline Belostoma & $0.28 \pm 0.06(6)$ & $1.00 \pm 0.00(6)$ & $29: 16 \pm 06: 18(6)$ \\
\hline
\end{tabular}

Note: Sample sizes are in parentheses.

$\dagger$ Only one of 14 Umbra struck at treefrogs; it missed one tadpole and consumed the other

$\ddagger$ Only two of seven Umbra struck at green frogs; one was missed, and one was spit out.

$\S$ Only one of six Umbra struck at bullfrogs, and all were spit out. 
tests (significant $P=0.025$ ). Anax found wood frogs, leopard frogs, treefrogs, and green frogs highly palatable, bullfrogs slightly unpalatable, and toads highly unpalatable. Umbra were only observed handling wood frogs and leopard frogs, and the latter took nearly four times longer to handle than the former; again the differences were nonsignificant following Bonferroni adjustment. Anax handled treefrogs in the shortest amount of time and spent progressively longer handling green frogs, bullfrogs, leopard frogs, toads, and wood frogs.

\section{Correlations between prey phenotypes and predation risk}

Predation risk vs. magnitude of response.-Given the above results on predation rates, the third hypothesis was that the differences in predation risk were correlated with the magnitude of phenotypic response. Using the first approach to this question, the withinprey/across-predators analysis, I found that predation risk and prey response were unrelated. The MANCOVA produced a significant effect of prey species (Wilks' $F_{45,47}=6.88, P<0.00001$ ), indicating that prey differed in their levels of response to predators, but the predation risk covariate was not significant (Wilks' $F_{9,10}=0.75, P=0.664$ ) nor was the prey-byrisk interaction (Wilks' $F_{45,47}=1.32, P=0.167$ ). In the univariate analyses, there were significant effects of activity $(P=0.01)$ and spatial avoidance $(P=0.01)$; increased predation risk was related to greater decreases in activity and greater increases in avoidance.

Using the second approach to this question, the within-predator/across-species analysis, there were significant correlations between predation risk and magnitude of prey responses (Fig. 2). In the presence of Um$b r a$, prey species that were at higher risk of predation exhibited greater decreases in activity $(P=0.001)$, greater increases in tail muscle depth $(P=0.022)$, and greater decreases in body length $(P=0.041)$ and width $(P=0.058)$. When the unpalatable toads were excluded from the analysis, prey species under higher predation risk also exhibited greater increases in tail fin depth $(P$ $=0.018)$; the other correlations remained similar. In the presence of Anax, prey species that were under higher predation risk also exhibited greater increases in tail fin depth $(P=0.001)$. The remaining phenotypic responses were not related to predation risk and the removal of toads had no effect on these results. Thus, of nine possible significant correlations within each predator, six $(67 \%)$ were significant in the presence of Umbra and one (11\%) was significant in the presence of Anax. If one makes a Bonferroni adjustment for conducting multiple (18) correlations, then the criterion for significance of any single correlation becomes $P<$ 0.003 . This leads to the conclusion that higher predation risk across species only leads to greater decreases in activity in the presence of Umbra and greater increases in tail depth in the presence of Anax.

Effects of prey phenotypes on predation risk.-The

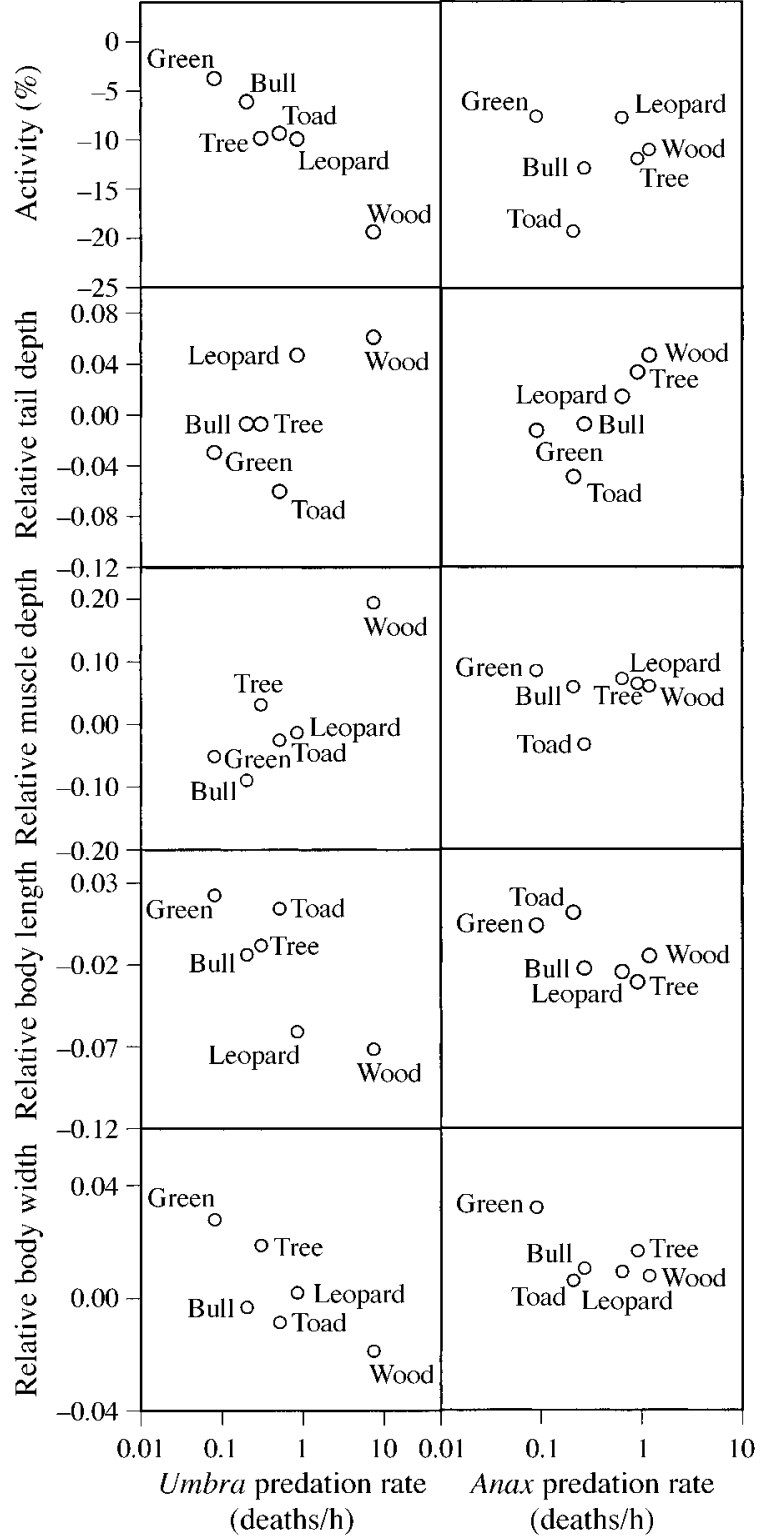

FIG. 2. The effect of predation risk by Umbra (left panels) and Anax (right panels) on the magnitude of selected phenotypic responses by six species of larval anuran prey. Morphological traits are size-adjusted as described in Relyea (2001). Species abbreviations are as follows: bull = bullfrog, green $=$ green frog, wood $=$ wood frog, leopard $=$ leopard frog, tree $=$ gray treefrog, and toad $=$ American toad. Note $\log$ scale.

fourth hypothesis was that differences in predation risk could be explained, at least in part, by difference in prey phenotypes. In the presence of Anax, none of the prey traits met the stepwise criterion $(P<0.15)$ to be added to the regression model. However, for many prey traits, toads were an outlier from the other five species (probably due to their extreme unpalatability to Anax). When toads were removed from the analyses (Fig. 3), 


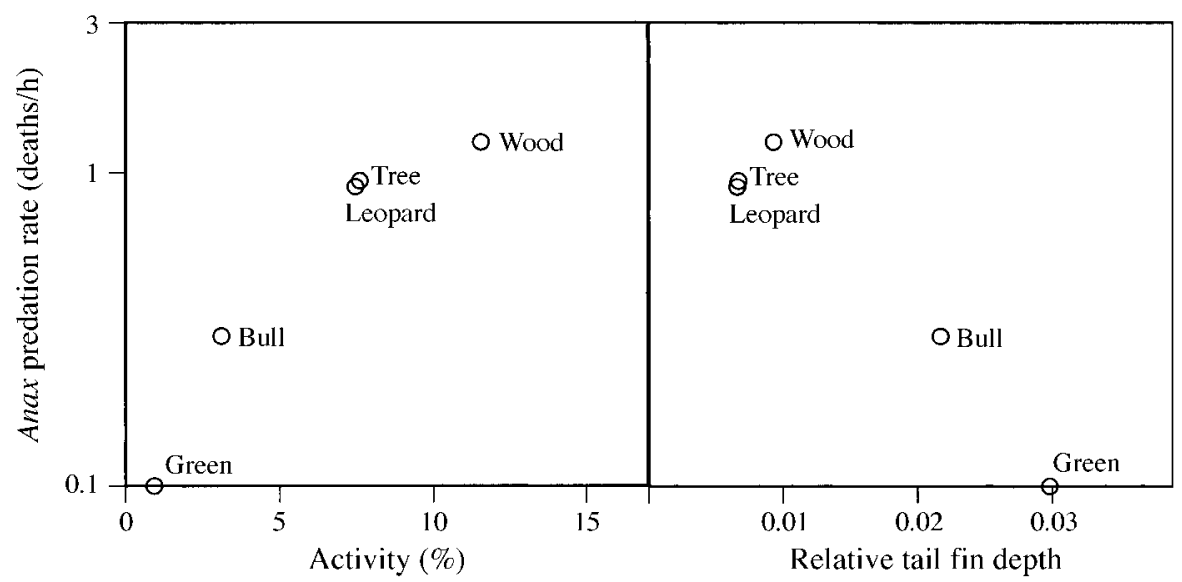

FIG. 3. The effect of activity and tail fin depth on predation rate by Anax across five species of larval anurans. Tail fin depth is size-adjusted as described in Relyea (2001). See Fig. 2 for species abbreviations. Note log scale.

differences in prey activity and tail depth were retained in the model, resulting in a significant regression model $\left(P=0.015, R^{2}=0.985\right)$. The model suggests that tadpoles with higher activity and shallower tails were killed more often. In the presence of Umbra, none of the behavioral or morphological traits met the significance criteria to be entered into the regression model and there was no pattern to the identity of any outliers for the nine traits. The Bonferroni criterion for conducting the two tests was $P<0.025$; thus the Anax result remained significant.

Effects of prey phenotypes on predator behavior.The fifth hypothesis was that the differences in predation risk among the six prey could be further broken down mechanistically to show that morphological differences among the prey affect a predator's ability to capture, handle, and consume prey. These cross-species comparisons were only conducted for Anax, because the other predator treatment that was common to all prey (Umbra) consumed few or no tadpoles for four of the six prey species. As a result, there is very low power to detect significant relationships given the six data points available. The univariate analyses showed that Anax had a higher probability of capturing tadpoles with shallower tails $(P=0.044)$ and wider bodies $(P$ $=0.027)$. Only the latter trait met the criteria to enter the stepwise regression model (multivariate $P=0.027$, $R^{2}=0.742$ ). The Bonferroni criterion for conducting the three regressions of the fifth hypotheses is $P<$ 0.017 ; thus, the relationship between morphology and capture success was nonsignificant. I did not conduct subsequent analyses excluding toads since the high unpalatability of toads was not likely to affect the percentage of Anax strikes that resulted in successful captures. When I analyzed the effect of prey morphology on Anax handling times, none of the traits were significantly related to handling time (for all univariate regressions, $P>0.35$ ); Anax handled most prey for $\sim 2$ min, regardless of prey morphology. Finally, pal- atability exhibited significant correlations with morphological traits. When toads were included in the regression analysis, anuran species with shallower tail fins and wider bodies (i.e., toads) were less palatable (multivariate $P=0.009, R^{2}=0.958$ ). However, when toads were excluded from the analysis, none of the morphological traits exhibited significant relationships (univariate $P>0.3$ ). Therefore, the relationships between morphological traits and palatability are best interpreted as an effect of toads being a single outlying point (representing low palatability), whereas the remaining anuran species had high palatability $(>80 \%)$.

\section{DISCUSSION}

The results of this experiment demonstrate that behavioral and morphological responses of larval anurans to predators generally are not related to predation risk. Rather, different prey employ different antipredator strategies against different predators. This result occurs because predators differ in how well they can encounter, capture, handle, and consume prey, and prey differ in traits that affect how well they can avoid encountering predators and escaping predator attacks. Below, I discuss the results of the predation rate experiment, how predation risk relates to prey responses, and how the abiotic environment limits the phenotypic responses observed in larval anurans.

Evidence of differences in predation rates among prey by a given predator and among predators on different prey are relatively common in the literature. Different prey species frequently vary in their risk of predation because they exhibit different behaviors (Morin 1986, Lawler 1989, McPeek 1990, Werner 1991, Grill and Juliano 1996), possess different defensive structures (Havel 1985, Kohler and McPeek 1989), or differ in palatability (Voris and Bacon 1966, Walters 1975, Kruse and Francis 1977, Kruse and Stone 1984). Similarly, different predator species frequently vary in the 
mortality they cause due to differences in predator foraging strategies (Brodie et al. 1978, McPeek 1990).

Similar to these studies, I also found differences in predation rates among predator-prey pairs. The differences in the predation rates among all of the predatorprey pairs cannot be attributed to differences in the sizes of the predators. In the analyses of predation by a single predator species across prey species, there was little difference in the sizes of the individual predators used (Table 1). Furthermore, three of the four predators used for the spring-breeding anurans (Anax, Notophthalmus, and Dytiscus) and two of the four predators used in the summer-breeding anurans (Anax and Ambystoma) were similar in size. However, predators of similar size imposed predation rates that differed by as much as an order of magnitude. These results support past studies that similar-sized predators are often not substitutable in ecological communities because they can often have very different effects on prey survival (Wilbur and Fauth 1990, Kurzava and Morin 1998).

The highest predation rates that I observed were for the two predator-prey combinations that are least likely to coexist with each other in natural ponds on the ESGR (E. E. Werner et al., unpublished data). Ambystoma predation on bullfrogs and Umbra predation on wood frogs were nearly an order of magnitude greater than the predation rate between any other pairs. This suggests that predation might be responsible for preventing coexistence between these pairs. Furthermore, it suggests that the two prey have not developed sufficient antipredator responses to their respective predators because the risk of actually encountering the predator in a natural pond is quite low, an observation made in other taxa as well (Brooks and Dodson 1965, Juliano and Reminger 1992, Werner and McPeek 1994).

Phenotypic differences among prey affected their risk from a single predator species. Among the five relatively palatable prey, the more active species were killed more often by Anax. This relationship has been predicted by theory (Gerritsen and Strickler 1977, Houston et al. 1993, Werner and Anholt 1993, McNamara and Houston 1994) and observed empirically in a number of studies (Chovanec 1992, Semlitsch 1993, Skelly 1994, Grill and Juliano 1996). Anax also preyed more heavily on prey with shallow tail fins and this pattern also has been documented within species (Van Buskirk et al. 1997, Van Buskirk and Relyea 1998). Research into the kinematics of swimming suggests that deeper tail fins should increase thrust (Wassersug and Hoff 1985) and improve swimming speed (McCollum and Leimberger 1997). Increased swimming speed is known to improve the ability to escape predators (Feder 1983, Figiel and Semlitsch 1991, Jung and Jagoe 1995, Watkins 1996, Raimando et al. 1998). The correlation between morphological traits and predator behavior was consistent with the mechanism of deeper tails improving swimming ability; increased tail fin depth was important at the capture stage of the predation process. In contrast to the Anax results, predation on the six prey species by Umbra was not correlated with prey phenotype. Given that Umbra rarely struck at four of the six species and at least three of the four are generally unpalatable to fish (Kruse and Stone 1984; Werner and McPeek 1994; see Results), it may be that palatability is the dominant factor in determining predation risk from Umbra. Because Umbra would rarely strike at some prey species, I did not have adequate data to test this hypothesis.

The correlations between prey phenotype and predator behavior improve our mechanistic understanding of the predation process in larval anurans. Prey activity and spatial distribution are thought to be the primary determinants of how frequently predators and prey encounter each other (Gerritsen and Strickler 1977, Werner and Anholt 1993). However, these behaviors should not affect the probability of being captured and consumed by predators once encountered. The benefit of predator-induced morphology occurs at the capture phase of the predation event; deep-tailed, narrow-bodied tadpoles escaped Anax better. The remaining stages of the predation event, handling time and probability of consumption (palatability) appear to be unaffected by differences in tadpole morphology.

Whereas palatability was not related to morphology, palatability was predator and prey specific. Toads provide the best example of how palatability varied among predators; toads were always rejected by Umbra, almost always rejected by Anax, rejected about half the time by Notophthalmus, and never rejected by Dytiscus. Some predator species may find tadpoles palatable because they are able to avoid the noxious substances that are thought to be located in the tadpole skin (Heyer et al. 1975). This may explain why the two piercing and sucking predators, Dytiscus and Belostoma, never rejected toads or bullfrogs in this study; they digest the inner tissues of the tadpoles and discard the skin. In past studies, premetamorphic Bufo sp. were consistently consumed by piercing and sucking predators (Brodie et al. 1978, Formanowicz and Brodie 1982, Peterson and Blaustein 1992) and consistently rejected by chewing predators (Voris and Bacon 1966, Kruse and Stone 1984). Leopard frogs present another excellent example of predator-specific palatability; they were moderately unpalatable to Umbra (rejected half of the time), but never rejected by the other three predators. The moderate unpalatability of leopard frogs to Umbra is not even a generalized unpalatability to fish predators. Kruse and Francis (1977) found that leopard frogs were highly palatable to largemouth bass ( $M i$ cropterus salmoides), green sunfish (Lepomis cyanellus), and black bullhead (Ictalurus melas). In overnight predation trials, I have found that bluegill sunfish ( $L e-$ pomis macrochirus) consumed an average of $19 \pm 1$ out of 20 leopard frog larvae available (unpublished data). 


\section{The relation between predation risk and antipredator response}

When I analyzed the relationship between predation risk and antipredator response within-prey/across predators, there was no significant multivariate relationship between risk and response, but there were significant univariate responses for antipredator behaviors. This result suggests that there $i$ a relationship between risk and response for behavioral traits but not for morphological traits and not for all traits combined in multivariate space. Together, these results suggest that prey are not using one suite of antipredator responses that are simply scaled to fit the current predation risk. Rather, prey are employing predator-specific defense strategies. The tadpoles in this study have a plethora of potential predator defenses. Tadpoles were able to alter at least two behavioral traits and several morphological traits that I measured in response to predators. Layered over this multitude of potential phenotypic combinations are differences in palatability that also are predator specific. Thus, prey possess many possible strategies to defend against predators and there is little consistency in how a particular prey species responds to different predators. For example, bullfrogs and toads experience similar predation rates in the presence of Anax, but bullfrogs accomplish it through low activity (bullfrogs $=3 \%$ vs. toads $=15 \%$ ) and lower capture efficiency by Anax (bullfrogs $=53 \%$ vs. toads $=$ $100 \%)$, whereas toads accomplish it though low palatability (bullfrogs $=79 \%$ vs. toads $=8 \%$ ). This conclusion of unique antipredator strategies is consistent with the results of the companion paper (Relyea 2001) in which I found that the behavioral and morphological responses of tadpoles were predator and prey specific.

The relationship between predation risk and magnitude of response across prey demonstrated patterns in how different prey respond to the risk of a particular predator. Past workers on prey responses to predators have concluded that there is generally a direct relationship between predation risk and the magnitude of the antipredator behavioral responses across species (Sih 1987, Lima and Dill 1990, Short and Holomuzki 1992, Peckarsky 1996) although there are exceptions (Abrahams and Healey 1993). In my study, prey species that faced higher predation risk from Umbra exhibited greater decreases in activity, which should result in fewer predator encounters (see Results; Werner and Anholt 1993, Skelly 1994, Grill and Juliano 1996). In addition, species that faced higher predation risk from Anax exhibited greater increases in tail depth, which should result in better swimming speed (Wassersug and Hoff 1985, McCollum and Leimberger 1997), decreased capture success (see Results), and lower predation rates (McCollum and Van Buskirk 1996, Van Buskirk et al. 1997, Van Buskirk and Relyea 1998). Thus, the magnitude of morphological and behavioral responses across prey species can be related to pre- dation risk, although the proportion of traits that exhibit significant relationships remains low.

\section{Conclusions}

In this study, I have demonstrated that phenotypic responses of a given prey to different predators generally are not correlated to the predation risk of those predators. Prey responses are both predator and prey specific because predation risk is predator and prey specific. Future work should focus on several areas. We are beginning to understand the function of some of the phenotypic responses of prey in response to predators, but we do not understand many others. One approach that has proven quite successful is the induction of alternative phenotypes and subsequent testing of their performance (Havel and Dodson 1984, Dudley and Schmitt 1996, Van Buskirk and Relyea 1998). Recent selection studies revealed that Anax not only induces a deeper tail fin and smaller body but also causes selection for individuals possessing that phenotype (Van Buskirk et al. 1997, Van Buskirk and Relyea 1998). Given that other predator species induce different phenotypic responses, one might predict that these predators also cause selection for different phenotypes; this prediction is a wide-open area of research. The patterns of risk and response observed in this group of larval anurans need to be tested in other anuran communities as well as in other taxa to determine if the conclusions reached in the current study are generally applicable to other systems. We will likely find that predation risk and prey responses are predator- and prey-specific, but we will only understand how these responses evolve by taking a more extensive approach, examining multiple traits of multiple species reared in multiple environments.

\section{ACKNOWLEDGMENTS}

I thank Scott Peacor for assistance with the field work, Sharmista JES'Son-Relyea for assistance in digitizing the tadpoles, and Ronald Nussbaum and Richard Alexander for providing access to the E. S. George Reserve. This manuscript was greatly improved by David Allan, Deborah Goldberg, Ronald Nussbaum, Earl Werner, and Kerry Yurewicz. This work was supported by University of Michigan research grants and NSF grants DEB-9119948 and DEB-9408397.

\section{Literature Cited}

Abrahams, M. V., and M. C. Healey. 1993. A comparison of the willingness of four species of Pacific salmon to risk exposure to a predator. Oikos 66:439-446.

Anholt, B. R., D. K. Skelly, and E. E. Werner. 1996. Factors modifying antipredator behavior in larval toads. Herpetologica 52:301-313.

Azevedo-Ramos, C., M. Van Sluys, J. Hero, and W. E. Magnusson. 1992. Influence of tadpole movement on predation by odonate naiads. Journal of Herpetology 26:335-338.

Ball, S. L., and R. L. Baker. 1996. Predator-induced life history changes: antipredator behavior costs or facultative life history shifts? Ecology 77:1116-1124.

Borash, D. J., A. G. Gibbs, A. Joshi, and L. D. Mueller. 1998. A genetic polymorphism maintained by natural selection in a temporally varying environment. American Naturalist 151:148-156. 
Bradshaw, A. D. 1965. Evolutionary significance of phenotypic plasticity in plants. Advances in Genetics 13:115155.

Brodie, E. D. J., D. R. J. Formanowicz, and E. D. I. Brodie. 1978. The development of noxiousness of Bufo americanus tadpoles to aquatic insect predators. Herpetologica 34:302306.

Brönmark, C., and J. G. Miner. 1992. Predator-induced phenotypical change in body morphology in Crucian carp. Science 258: $1348-1350$.

Brooks, J. L., and S. I. Dodson. 1965. Predation, body size, and composition of plankton. Science 150:28-35.

Chovanec, A. 1992. The influence of tadpole swimming behaviour on predation by dragonfly nymphs. Amphibia-Reptilia 13:341-349.

Crowl, T. A., and A. P. Covich. 1990. Predator-induced lifehistory shifts in a freshwater snail. Science 247:949-951.

Dill, L. M. 1987. Animal decision making and its ecological consequences: the future of aquatic ecology and behaviour. Canadian Journal of Zoology 65:803-811.

Dudley, S. A., and J. Schmitt. 1996. Testing the adaptive plasticity hypothesis: density-dependent selection on manipulated stem length in Impatiens capensis. American Naturalist 147:445-465.

Feder, M. E. 1983. The relation of air-breathing and locomotion to predation on tadpoles, Rana berlandieri, by turtles. Physiological Zoology 56:522-531.

Figiel, C. R., Jr., and R. D. Semlitsch. 1991. Effects of nonlethal injury and habitat complexity on predation in tadpole populations. Canadian Journal of Zoology 69:830-834

Formanowicz, D. R. J., and E. D. J. Brodie. 1982. Relative palatabilities of members of a larval amphibian community. Copeia 1982: 91-97.

Gerritsen, J., and J. R. Strickler. 1977. Encounter probabilities, and the community structure in zooplankton: a mathematical model. Journal of the Fisheries Board of Canada 34:73-82.

Gomulkiewicz, R., and M. Kirkpatrick. 1992. Quantitative genetics and the evolution of reaction norms. Evolution 46: 390-411.

Grant, P., and R. Grant. 1995. Predicting microevolutionary responses to directional selection on heritable variation. Evolution 49:241-251.

Grill, C. P., and S. A. Juliano. 1996. Predicting species interactions based on behaviour: predation and competition in container-dwelling mosquitoes. Journal of Animal Ecology 65:63-76.

Harvell, C. D. 1990. The ecology and evolution of inducible defenses. Quarterly Review of Biology 65:323-340.

Hassell, M. P., and T. R. E. Southwood. 1978. Foraging strategies of insects. Annual Review of Ecology and Systematics 9:75-98.

Havel, J. E. 1985. Predation of common invertebrate predators on long- and short-featured Daphnia retrocurva. Hydrobiologia 124:141-149.

Havel, J. E. 1987. Predator-induced defenses: a review. Pages 263-278 in W. C. Kerfoot and A. Sih, editors. Predation: direct and indirect impacts on aquatic communities. University Press of New England, Hanover, New Hampshire, USA.

Havel, J. E., and S. I. Dodson. 1984. Chaoborus predation on typical and spined morphs of Daphnia pulex: behavioral observations. Limnology and Oceanography 29:487-494.

Havel, J. E., and S. I. Dodson. 1987. Reproductive costs of Chaoborus-induced polymorphism in Daphnia pulex. $\mathrm{Hy}$ drobiologia 150:273-281.

Heyer, W. R., R. W. McDiarmid, and D. L. Weigmann. 1975. Tadpoles, predation and pond habitats in the tropics. Biotropica 7:100-111.

Houston, A. I., J. M. McNamara, and J. M. C. Hutchinson.
1993. General results concerning the trade-off between gaining energy and avoiding predation. Philosophical Transactions of the Royal Society of London B 341:375397.

Juliano, S. A., and L. Reminger. 1992. The relationship between vulnerability to predation and behavior of larval treehole mosquitoes: geographic and ontogenetic differences. Oikos 63:465-476.

Jung, R. E., and C. H. Jagoe. 1995. Effects of low pH and aluminum on body size, swimming performance, and susceptibility to predation of green treefrog (Hyla cinerea) tadpoles. Canadian Journal of Zoology 73:2171-2183.

Kats, L. B., J. W. Petranka, and A. Sih. 1988. Antipredator defenses and the persistence of amphibian larvae with fishes. Ecology 69:1865-1870.

Kingsolver, J. G. 1995a. Fitness consequences of seasonal polyphenism in western white butterflies. Evolution 49: 942-954.

Kingsolver, J. G. 1995b. Viability selection on seasonally polyphenic traits: wing melanin pattern in western white butterflies. Evolution 49:932-941.

Kohler, S. L., and M. A. McPeek. 1989. Predation risk and the foraging behavior of competing stream insects. Ecology 70:1811-1825.

Kruse, K. C., and M. G. Francis. 1977. A predation deterrent in larvae of the bullfrog, Rana catesbeiana. Transactions of the American Fisheries Society 106:248-252.

Kruse, K. C., and B. M. Stone. 1984. Largemouth bass (Micropterus salmoides) learn to avoid feeding on toad (Bufo) tadpoles. Animal Behaviour 32:1035-1039.

Kurzava, L. M., and P. J. Morin. 1998. Tests of functional equivalence: complementary roles of salamanders and fish in community organization. Ecology 79:477-489.

Kusch, J. 1993. Behavioral and morphological changes in ciliates induced by the predator Amoeba proteus. Oecologia 96:354-359.

Lawler, S. P. 1989. Behavioural responses to predators and predation risk in four species of larval anurans. Animal Behaviour 38:1039-1047.

Lima, S. L., and L. M. Dill. 1990. Behavioral decisions made under the risk of predation: a review and prospectus. Canadian Journal of Zoology 68:619-640.

Losos, J. B. 1990. A phylogenetic analysis of character displacement in Caribbean Anolis lizards. Evolution 44:558569.

McCollum, S. A., and J. D. Leimberger. 1997. Predator-induced morphological changes in an amphibian: predation by dragonflies affects tadpole shape and color. Oecologia 109:615-621.

McCollum, S. A., and J. Van Buskirk. 1996. Costs and benefits of a predator-induced polyphenism in the gray treefrog Hyla chrysoscelis. Evolution 50:583-593.

McNamara, J. M., and A. I. Houston. 1994. The effect of a change in foraging options on intake rate and predation rate. American Naturalist 144:978-1000.

McPeek, M. A. 1990. Behavioral differences between Enallagma species (Odonata) influencing differential vulnerability to predators. Ecology 71:1714-1726.

McPeek, M. A. 1997. Measuring phenotypic selection on an adaptation: lamellae of damselflies experiencing dragonfly predation. Evolution 51:459-466.

Moran, N. A. 1992. The evolutionary maintenance of alternative phenotypes. American Naturalist 139:971-989.

Morin, P. J. 1986. Interactions between intraspecific competition and predation in an amphibian predator-prey system. Ecology 647:713-720.

Peckarsky, B. L. 1996. Alternative predator avoidance syndromes of stream-dwelling mayfly larvae. Ecology 77: $1888-1905$

Peterson, J. A., and A. R. Blaustein. 1992. Relative palat- 
abilities of anuran larvae to natural aquatic insect predators. Copeia 1992: 577-584.

Petranka, J. W., L. B. Kats, and A. Sih. 1987. Predator-prey interactions among fish and larval amphibians: use of chemical cues to detect predatory fish. Animal Behavior 35:420-425.

Pettersson, L. B., and C. Brönmark. 1997. Density-dependent costs of an inducible morphological defense in crucian carp. Ecology 78:1805-1815.

Raimando, S. M., C. L. Rowe, and J. D. Congdon. 1998. Exposure to coal ash impacts swimming performance and predator avoidance in larval bullfrogs (Rana catesbeiana). Journal of Herpetology 32:289-292.

Relyea, R. A. 2001. Morphological and behavioral plasticity of larval anurans in response to different predators. Ecology 82:523-540.

Reznick, D. N., H. Bryga, and J. A. Endler. 1990. Experimentally induced life-history evolution in a natural population. Nature 346:357-359.

Schlichting, C. D. 1986. The evolution of phenotypic plasticity in plants. Annual Review of Ecology and Systematics 17:667-693.

Schluter, D. 1994. Experimental evidence that competition promotes divergence in adaptive radiation. Science 266: 798-801.

Semlitsch, R. D. 1993. Effects of different predators on the survival and development of tadpoles from the hybridogenetic Rana esculenta complex. Oikos 67:40-46.

Short, T. M., and J. R. Holomuzki. 1992. Indirect effects of fish on foraging behaviour and leaf processing by the isopod Lirceus fontinalis. Freshwater Biology 27:91-97.

Sih, A. 1987. Predators and prey lifestyles: an evolutionary and ecological overview. Pages 203-224 in W. C. Kerfoot and A. Sih, editors. Predation: direct and indirect impacts on aquatic communities. University Press of New England, Hanover, New Hampshire, USA.

Skelly, D. K. 1994. Activity level and the susceptibility of anuran larvae to predation. Animal Behaviour 47:465-468.

Skelly, D. K., and E. E. Werner. 1990. Behavioral and lifehistorical responses of larval American toads to an odonate predator. Ecology 71:2313-2322.

Sultan, S. E. 1987. Evolutionary implications of phenotypic plasticity in plants. Evolutionary Biology 21:127-177.

Travis, J. 1994. Evaluating the adaptive role of morphological plasticity. Pages 99-122 in P. C. Wainwright and S. M.
Reilly, editors. Ecological morphology. University of Chicago Press, Chicago, Illinois, USA.

Van Buskirk, J., S. A. McCollum, and E. E. Werner. 1997. Natural selection for environmentally-induced phenotypes in tadpoles. Evolution 52:1983-1992.

Van Buskirk, J., and R. A. Relyea. 1998. Natural selection for phenotypic plasticity: predator-induced morphological responses in tadpoles. Biological Journal of the Linnean Society 65:301-328.

Via, S., R. Gomulkiewicz, G. De Jong, S. M. Scheiner, C. D. Schlichting, and P. H. Van Tienderen. 1995. Adaptive phenotypic plasticity: consensus and controversy. Trends in Ecology and Evolution 10:212-217.

Via, S., and R. Lande. 1985. Genotype-environment interaction and the evolution of phenotypic plasticity. Evolution 39:502-522.

Voris, H. K., and J. P. J. Bacon. 1966. Differential predation on tadpoles. Copeia 1966: 594-598.

Walters, B. 1975. Studies of interspecific predation within an amphibian community. Journal of Herpetology 9:267279.

Wassersug, R. J., and K. Hoff. 1985. Kinematics of swimming in anuran larvae. Journal of Experimental Biology 119: $1-30$.

Watkins, T. B. 1996. Predator-mediated selection on burst swimming performance in tadpoles of the Pacific treefrog, Pseudacris regilla. Physiological Zoology 69:154-167.

Werner, E. E. 1991. Nonlethal effects of a predator on competitive interactions between two anuran larvae. Ecology 72: $1709-1720$

Werner, E. E., and B. R. Anholt. 1993. Ecological consequences of the trade-off between growth and mortality rates mediated by foraging activity. American Naturalist 142: 242-272.

Werner, E. E., and M. A. McPeek. 1994. Direct and indirect effects of predators on two anuran species along an environmental gradient. Ecology 75:1368-1382.

West-Eberhard, M. J. 1989. Phenotypic plasticity and the origins of diversity. Annual Review of Ecology and Systematics 20:249-278.

Wilbur, H. M., and J. E. Fauth. 1990. Experimental aquatic food webs: interactions between two predators and two prey. American Naturalist 135:176-204.

Woodward, B. D. 1983. Predator-prey interactions and breeding-pond use of temporary-pond species in a desert anuran community. Ecology 64:1549-1555. 